\title{
Floating elbows in adults: epidemiology, clinical presentation, management and prognosis: Brazzaville Teaching Hospital experience
}

\author{
Monka Marius ${ }^{1 *}$, Ohoya Etsaka Terence Olivier ${ }^{1}$, Massamba Miabaou Didace ${ }^{2}$, \\ Ngatse Oko Albert ${ }^{1}$, Moyikoua Armand ${ }^{1}$
}

\begin{abstract}
${ }^{1}$ Department of Trauma-Orthopaedics, CHU-Brazzaville Teaching Hospital, Congo
${ }^{2}$ Department of Multipurpose Surgery, CHU-Brazzaville Teaching Hospital, Congo
\end{abstract}

Received: 29 November 2019

Accepted: 05 February 2020

*Correspondence:

Dr. Monka Marius,

E-mail: mar_monka@yahoo.fr

Copyright: ( ) the author(s), publisher and licensee Medip Academy. This is an open-access article distributed under the terms of the Creative Commons Attribution Non-Commercial License, which permits unrestricted non-commercial use, distribution, and reproduction in any medium, provided the original work is properly cited.

\begin{abstract}
Background: The objective of this study was to describe the epidemiological, clinical presentation, management and prognosis of classic floating elbows at the Brazzaville University hospital.

Methods: This is retrospective descriptive study conducted in the Trauma-Orthopedics Department at Brazzaville University Hospital between January 2013 and December 2018. Four patients meeting the inclusion criteria underwent surgery. Open fractures were classified according to the classification of Gustilo and Anderson. Anatomical evaluation was based on the quality of fracture reduction and bone healing. The functional results were assessed according to the Mayo Clinic score.

Results: The functional results were assessed according to the Mayo Clinic score of the 4 patients in our study, there were 3 men and 1 woman. The average age was 31 (28 and 34). They were all victims of traffic accidents. Three floating elbows were closed and one open at the humeral level with paralysis of the radial nerve. The closed fractures were treated by screwed plates and the open fracture by external fixator. Bone healing was achieved in 3 patients and we observed 1 case of aseptic nonunion of the radius. According to the Mayo Clinic score, 2 patients had a very good functional result, 1 patient an average result and 1 patient a poor result.

Conclusions: Classic floating elbows are rare and their prognosis remains unpredictable, especially when they involve musculo-cutaneous or neurovascular damages. Their treatment must be surgical in the adult to avoid a prolonged immobilization which may lead to stiffness of the elbow. A multidisciplinary approach should then be taken into consideration.
\end{abstract}

Keywords: Floating elbow, Classic, Adult

\section{INTRODUCTION}

The floating elbow is a rare and serious condition, especially when it is associated with damage of the soft tissue envelope (Open floating elbow) or neuro-vascular injury. First described in children by Stanitski and Micheli in 1980 then in adults by Rogers et al. ${ }^{1,2}$ it is as an association of fractures involving the humerus and the bones of the ipsilateral forearm isolating the elbow joint from the rest of the thoracic limb. Several series have reported classic floating elbows (association of fracture of the humeral shaft and diaphyseal fractures of the bones of the ipsilateral forearm) and non-classic floating elbows (combination of diaphyseal and epiphyseal fractures or epiphyseal fractures of the humerus and epiphyseal bones of the ipsilateral forearm) in children and adults. ${ }^{3-6}$ They are usually due to high-energy trauma. Standard X-Ray of the humerus and ipsilateral forearm bones showing the upper and lower joints remains the first choice for diagnosis. The management of floating elbows is surgical 
in the adult in order to stabilize and ensure early mobilization of the elbow and prevent joint stiffness. However, when the trauma includes damages of soft or nervous tissues, their prognosis is unpredictable. The aim of this study was to assess the epidemiology, presentation management and prognosis of classic floating elbows managed at Brazzaville Teaching Hospital.

\section{METHODS}

\section{Patients}

We report a descriptive retrospective series of patients hospitalized and treated for classic floating elbow in the department of Trauma-Orthopedic at Brazzaville Teaching Hospital between January 2013 and December 2018. 7 patients were recruited. We included 4 patients aged over 15 years, presenting classic floating elbows. Patients younger than 15 years, presenting non-classic floating elbows were excluded. Open fractures were classified according to the classification of Gustillo and Anderson. ${ }^{7}$

\section{Surgical technique and postoperative care}

All floating elbows were managed surgically. A screwed plate was used for closed fractures. One open fracture involving the humerus, associated with bone loss and classified as type IIIb according to the Gustillo and Anderson classification, was stabilized by an external fixator. The assembly was humero-humeral, with screwing of an intermediate fragment. Antibiotic treatment was provided in the patient with open fracture and antibio prophylaxis was administered in patients with closed fractures. Functional rehabilitation of the affected thoracic limb was systematic from the second postoperative day and continued in a specialized center.

\section{Evaluation methods}

Anatomical evaluation was based on the quality of fracture reduction and bone healing. The functional results were evaluated according to the Mayo Clinic score 8 based on 4 criteria including pain, mobility bow, stability and functional capacity.

\section{RESULTS}

\section{Epidemiological aspects}

During the study period 2140 patients were hospitalized for limb fractures. 7 patients ( $0.3 \%$ of cases) had a classic floating elbow. The selected 4 patients in our study, were all involved in traffic accidents. They were 3 males, and 1 female. Their average age was 31 (28 and 34) (Figure 1).

\section{Presentation}

The floating elbow was classic in all 4 patients. Three floating elbows were closed and one open at the humeral level and classified type IIIb of Gustillo and Anderson with paralysis of the radial nerve. Trauma involving the left thoracic limb occurred 3 times, while the right thoracic limb was involved 1 time.

\section{Management}

Therapeutically, closed floating elbows were treated by screwed plate (Figure 2). In the patient with an open floating elbow, the humeral fracture was managed by external fixator. Fractures of both forearm bones were managed by screwed plates (Figure $3 \mathrm{a}$ and b). The average operating time was 8 days (range 5 to 13 days).

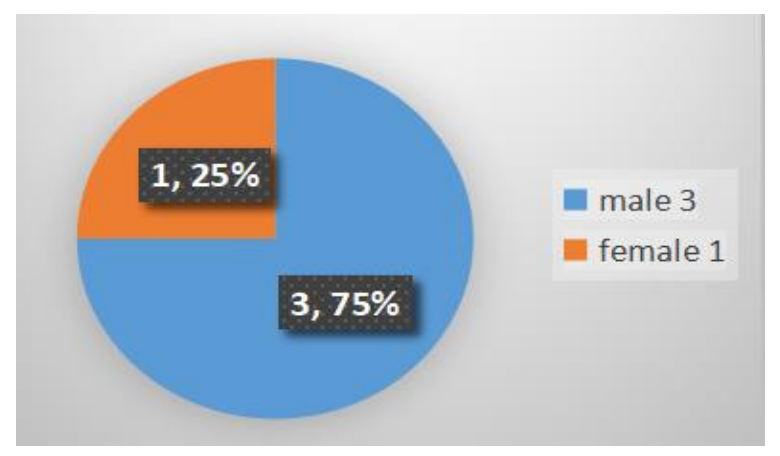

Figure 1: Distribution of sex.
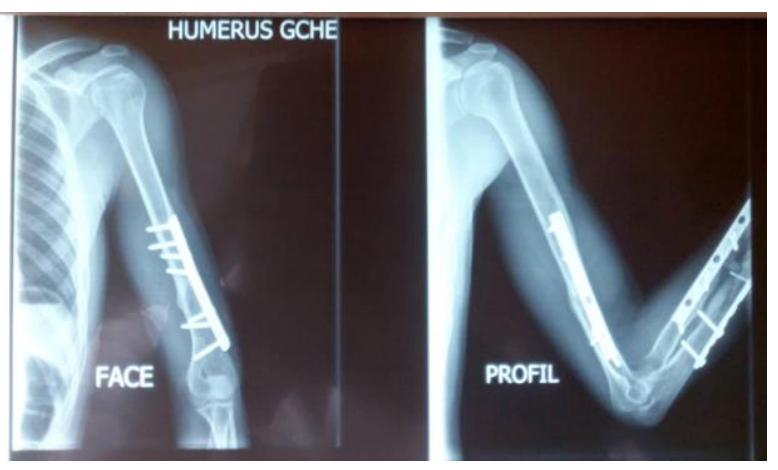

Figure 2: Complete bone healing of all fragments on screwed plate.

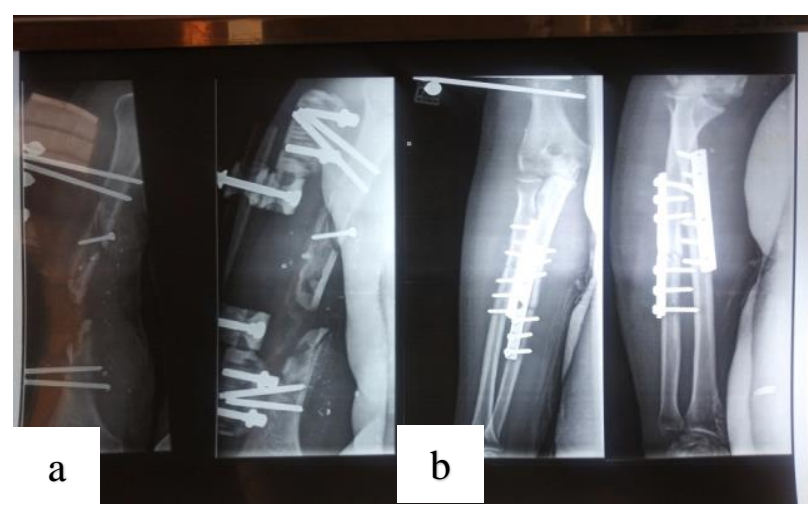

Figure 3 (a and b): Floating elbow with bone loss managed with external fixation humerus and screwed plate forearm. 


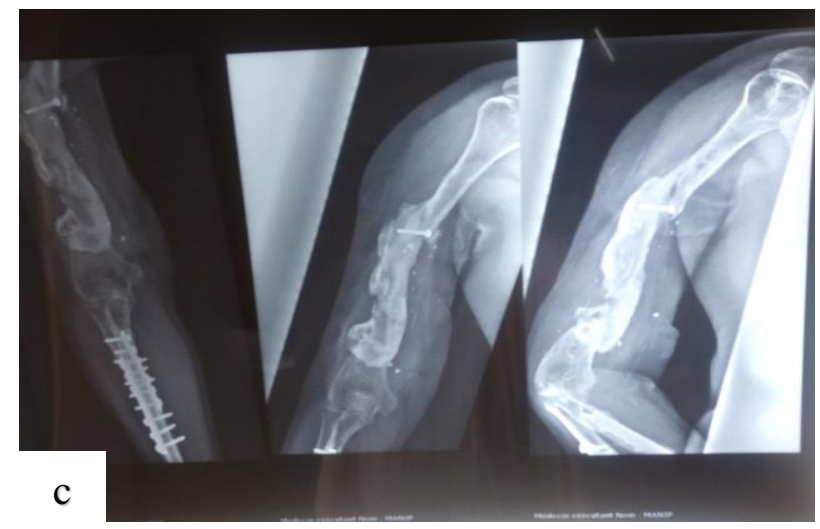

Figure 3c: Osteitis of the humerus observed 20 months following bone graft.

\section{Prognosis}

Bone healing was achieved in 3 patients and 1 developed aseptic non-union of the radius, requiring surgical revision, but was denied by the patient. Among the 3 patients who achieved bone healing, 1 developed osteitis of the humerus with the presence of a chronic fistula complicating an open type IIIB fracture of Gustillo and Anderson (Figure 3c). This complication was observed after bone grafting. The recovery of radial paralysis was partial. Functionally, elbow stiffness was associated with limitation of prono-supination in one patient and was isolated in 1 patient. According to the Mayo Clinic score, 2 patients had a very good functional result, 1 patient an average result and 1 patient a poor result.

\section{DISCUSSION}

The rarity of floating elbows has been reported by several authors. ${ }^{6-9}$ During the last 6 years, we observed 7 cases $(0.3 \%)$. Trigui M. Kazuhiko Yokoyama and Anoumou NM. respectively ported 10 cases in 5 years, 14 cases in 10 years and 14 cases in 11 years, respectively. On the other hand, Lamah et al reported an incidence of $5.4 \%$ in their series with a diversity of floating elbows. ${ }^{4-9}$

The average age of our patients was 31 years old. These results are almost identical to those presented by Trigui et al who report an average age of 32 years. ${ }^{4}$ Anoumou and al., Lamah and report an average age of 45 years and 39.13 years, respectively. ${ }^{6-9}$ In light of these results, the floating elbows constitute a traumatic condition of the young subject. Male predominance has been reported in our series as well as in the various studies by several authors. $^{4}$

In regards to the etiology, all our patients were victims of traffic accidents. This result is identical to that of Lamah et al. Road accidents represent the first cause of floating elbows in most series. ${ }^{9}$ Floating elbows occur as a result of high energy trauma, sometimes involving soft tissue and / or neuro-vascular injury. ${ }^{3-10}$
Considering the site of injury, the left thoracic limb was involved 3 times and the right thoracic limb 1 time in our study. The predominance of left hemisphere has been found in other studies. ${ }^{6-9}$

Considering the management, the choice of treatment depends on the presentation of the floating elbow. Non displaced ipsilateral diaphyseal fractures of the humerus and the forearm can be treated with orthopedic plaster in children and in adults. ${ }^{6-11}$

This option is widely used in children. ${ }^{11}$ The plaster immobilization blocking the upper and lower joints until complete healing, presents little benefit in adults, especially when in case of displaced fractures of one or both bones from the forearm.

At present, the majority of authors promote surgical treatment in adults to avoid prolonged immobilization leading to elbow stiffness. ${ }^{9}$

The 3 closed fractures in our study was treated by internal osteosynthesis and 1 open fracture by external fixation. One patient with an open fracture presented paralysis of the radial nerve.

Radial nerve paralysis during humeral shaft fractures has been reported in different studies. ${ }^{3-9}$

Considering the prognosis, we noted a case of elbow stiffness and 1 case of aseptic non-union of the radius, associated with a stiffness of the elbow and a limitation of the prono-supination. Other authors have observed the same complications of fractures. ${ }^{2-9}$ Elbow stiffness and non-union are very common in trauma. They cause a significant functional disability in professional life.

According to the Mayo Clinic score, our results were very good in 2 patients, average in 1 patient and bad in 1 patient. The functional results of closed floating elbows are generally better after adequate and early surgical management, except in cases of associated soft tissue or nerve lesions where the functional prognosis is unpredictable. The average and poor results observed in our series were caused by soft tissue and nerve injury and probably by the quality of the surgical technique that could have caused damage of the periosteum.

\section{CONCLUSION}

Classic floating elbows rare. Their outcome depends on a lot of conditions, early and adequate management. Their prognosis remains unpredictable in cases involving muscle, skin and nerve injury. A multidisciplinary approach should then be taken into consideration.

Funding: No funding sources

Conflict of interest: None declared

Ethical approval: The study was approved by the institutional ethics committee 


\section{REFERENCES}

1. Stanitski CL, Micheli LJ. Simultaneous ipsilateral fractures of the arm and forearm in children. Clin Orthop Relat Res. 1980;(153):218-22.

2. Rogers JF, Benett JB, Tullos HS. Management of concomitant ipsilateral fractures of humerus and forearms. J Bone Joint Surg (AM). 1984;66:552-5.

3. Cho $\mathrm{C}-\mathrm{H}$, Min K-K. Classic Floating Elbow in Adults: A Case Series. Clin Shoulder Elbow. 2015;18(1):8-12.

4. Trigui M, Khemakhem Z, Sallemi J, Bouaziz W, Ellouz Z, Zribi M, et al. Le coude flottant chez l'adulte : aspects cliniques et médicolégaux. J. I.M. Sfax 2018;29:38-46.

5. Yokoyama K, Itoman M, Kobayashi A, Shindo M, Futami T. Functional outcomes of "floating elbow" injuries in adult patients. J Orthop Trauma. 1998;12(4):284-90.

6. Anoumou NM, Gogoua D, Assiobo A, Kone B, Fal A, Guedegbe F, et al. Coude flottant et derives: aspects nosologiques et resultats therapeutiques a propos de 7 cases. Rev Cames- serie. 2006;4:13-7.

7. Gustillo RB, Mendoza RB, William DN. Problems in the management of type III (severe) open fractures: a new classification of type III open fractures. J Trauma. 1984;24:742-6.
8. Morrey BF, Adams RA. Semiconstrained arthroplasty for the treatment of rheumatoid arthritis of the elbow. J Bone Joint Surg Am. 1992;74:47990.

9. Lamah L, Diakite SK, Kallo OF, Toure M, Diallo MM, Kourouma F, Diallo IG, Diallo I. Coudes Flottants: aspects anatomo-cliniques et al. analyse du traitement. Mali Medical. 2013;28(4):9-12.

10. Jockel CR, Gardenal RM, Chen NC, Golden RD, Jupiter JB, Capomassi M. Intermediate-term outcomes for floating elbow and floating elbow variant injuries. J Shoulder Elbow. 2013;22(2):2805.

11. Harrington P, Sharif I, Fogarty EE, Dowling FE, Moore DP. Management of the floating elbow injury in children. Simultaneous ipsilateral fractures of the elbow and forearm. Acta Orthop Trauma Surg. 2000;120:205-8.

Cite this article as: Marius M, Olivier OET, Didace MM, Albert NO, Armand M. Floating elbows in adults: epidemiology, clinical presentation, management and prognosis: Brazzaville Teaching Hospital experience. Int J Res Orthop 2020;6:323-6. 